\title{
Case-control studies of relation between childhood cancer and neonatal vitamin $\mathrm{K}$ administration
}

\author{
S Jane Passmore, Gerald Draper, Pat Brownbill, Mary Kroll
}

See editorial by

von Kries and

pp 173, 184, 189,

230

Childhood Cancer

Research Group,

Oxford OX2 6HJ

S Jane Passmore

research officer

Gerald Draper,

director

Pat Brownbill,

research programmer

Mary Kroll,

statistician

Correspondence to:

Dr Draper

gjd@ccrg.ox.ac.uk

BMJ 1998;316:178-84

\begin{abstract}
Objective: To investigate the possible link between neonatal administration of intramuscular vitamin $\mathrm{K}$ and childhood cancer.

Design: Matched case-control study.

Setting: Selected large maternity units in England and Wales.

Subjects: Children with cancer born 1968-85, diagnosed 1969-86; controls matched for sex, month of birth, and hospital of birth.
\end{abstract}

Main exposure measures: Neonatal administration of vitamin $\mathrm{K}$, length of gestation, birth weight, type of delivery, admission to special care baby unit.

Results: After exclusion of cases with missing notes or unknown hospital vitamin K policy, 597 cases and matched controls were studied. Written records on the use of vitamin $\mathrm{K}$ were available for only about $40 \%$ of these, and to avoid possible bias from selective recording it was assumed that the stated hospital policy was followed. The association between cancer generally and intramuscular vitamin $\mathrm{K}$ was of borderline significance (odds ratio $1.44, \mathrm{P}=0.05$ ); the association was strongest for leukaemia. There was, however, also an effect of abnormal delivery, which could explain some of the findings.

Conclusions: The lack of consistency between the various studies so far published, including this one, and the low relative risks found in most of them suggest that the risk, if any, attributable to the use of vitamin $\mathrm{K}$ cannot be large, but the possibility that there is some risk cannot be excluded. A comparison of the predicted consequences of various policies shows that even a $10 \%$ increase would imply that prophylaxis using the commonly recommended $1 \mathrm{mg}$ intramuscular dose should be restricted to babies at particularly high risk of vitamin $\mathrm{K}$ deficiency bleeding; alternatively a lower dose might be given to a larger proportion of those at risk.

\section{Introduction}

In the early 1990s Golding et al published two studies suggesting a link between intramuscular vitamin $\mathrm{K}$ (usually Konakion) given to babies for the prevention of vitamin $\mathrm{K}$ deficiency bleeding and subsequent childhood cancer. $^{12}$ Five further studies have been published: one from the United Kingdom, ${ }^{3}$ three from other parts of Europe, ${ }^{4-6}$ and one from the United States $^{7}$ (though not all the vitamin K preparations had the same constituents). These studies found no risk or risks much smaller than those reported by Golding, though many had wide confidence intervals.

Vitamin K, usually in the form of an intramuscular injection, has been used in the United Kingdom since the 1950 s for the prevention of vitamin K deficiency bleeding, though the proportion of babies given this prophylaxis has varied. In some hospitals and periods there has been a "non-selective" policy of treating all babies; in others there has been a "selective" policy of treating only a group thought to contain those at higher risk of vitamin $\mathrm{K}$ deficiency bleeding (variously defined but usually including assisted deliveries, low birthweight babies, and those admitted to special care-that is, about $30 \%$ of births).

After Golding's results were published the British Paediatric Association recommended that the use of intramuscular vitamin $\mathrm{K}$ should be confined to high risk babies and that the remainder should receive oral doses. The risk with oral vitamin $\mathrm{K}$ has been assumed by most people to be zero, although the Golding paper showed a (non-significant) raised risk of 1.15. In this paper we report the results of a case-control study and summarise the results of previous work.

\section{Methods}

The National Registry of Childhood Tumours maintained by the Childhood Cancer Research Group contains records of children diagnosed with cancer before the age of 15 years from 1962 onwards who were resident in England, Wales and Scotland. ${ }^{8}$ We included in this study children born in selected hospitals in 1968 or later and diagnosed by the end of 1986 with malignant tumours. We excluded retinoblastoma, children diagnosed before their 1st birthday, and children with Down's syndrome or neurofibromatosis. Sources of cases are described below.

Permission to use cancer registration data for this study was obtained through the Office of Population Censuses and Surveys-now part of the Office for National Statistics-and from the BMA medical ethics committee; hospital ethics committees gave permission to abstract hospital records.

\section{Selected maternity units}

We included 16 hospitals with large maternity units, mainly from the Trent and the West Midlands health authority regions of England, and ascertained their policies for administering vitamin $\mathrm{K}$ to newborns by using unpublished information from a survey by Handel and Tripp. ${ }^{9}$

Medical records of children known by us to have developed cancer were sought through hospital birth registers. Four controls matched for sex, month of birth, and hospital of birth were chosen from these registers. We excluded as controls those with illegible records, neonatal deaths, twins, and stillbirths; babies with severe neural tube defects or a birth weight of less than $1000 \mathrm{~g}$ were also excluded as these were unlikely to survive to the age at which the case developed cancer. For these an alternative control was selected by using the next suitable birth in the register. Information on mode of delivery, gestation, birth weight, and admission to special care baby units was abstracted if recorded in the birth register. This information was used to compile lists of names and 


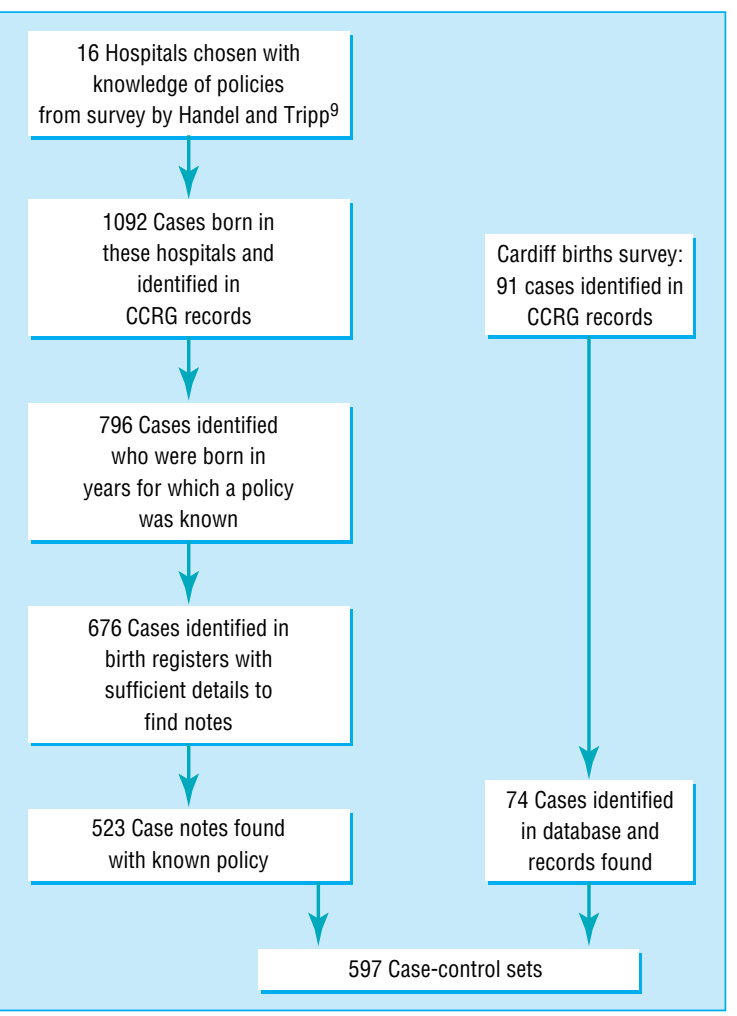

Details of origin of eligible cases

hospital numbers. Medical records departments were asked to locate records for each case and one control. We selected at random two of the four controls; if the records department was unable to locate the notes of either of these we supplied details of the other two. We used the obstetric notes to collect further perinatal information, in particular details of vitamin K. It was not possible for the abstracters to be blind to case or control status; however, the importance of a thorough search of all records for evidence of vitamin $\mathrm{K}$ having been given was impressed on them. During these hospital visits we collected information about vitamin $\mathrm{K}$ policies for the years not covered by the Handel-Tripp survey. ${ }^{9}$

\section{The Cardiff births survey}

A second group of cases chosen from the same time period was found by using records from the National Registry of Childhood Tumours to identify cases of cancer occurring among children included in the Cardiff births survey, which contains information on more than 100000 births in South Glamorgan. For each case we chose two controls matched for sex, month of birth, and hospital by using the exclusions described above. Medical records were sought for all cases and controls. Information on vitamin $\mathrm{K}$ administration taken from these records was supplemented by data from the Cardiff births survey, which contained data on vitamin $\mathrm{K}$ for most but not all of the period of the study. This added three further hospitals to the study, all of which had "selective" vitamin K policies.

\section{Statistical analysis}

The analysis was carried out with standard conditional logistic regression methods for studies with variable numbers of controls per case. ${ }^{11}$
Intramuscular vitamin $\mathrm{K}$ administration was categorised as Yes or No if it had been positively recorded as such in the medical records. For only about $40 \%$ was there a record in the notes relating to whether or not intramuscular vitamin $\mathrm{K}$ had been given, and it was assumed for the rest that the hospital policy had been followed. Only 10 babies had been given oral vitamin $\mathrm{K}$; these were coded as No. Other perinatal factors were categorised as: low birth weight $(<2500 \mathrm{~g})$ or normal/ high; admitted to special care baby units or not admitted; type of delivery abnormal (forceps, ventouse, breech, or caesarean) or normal; and gestation short $(<37$ weeks) or term. These factors were chosen on the grounds that they might be risk factors for childhood cancer and are certainly associated with the likelihood of vitamin $\mathrm{K}$ administration.

\section{Results}

We identified 1092 eligible cases (figure). Birth registers for some years were unavailable in some hospitals, and for the children born in these years we were unable to obtain the details required to find the mothers' notes. Records for some could not be traced; for others we could not be sure of the vitamin K policy. We found medical records and were able to categorise vitamin $\mathrm{K}$ status for 523 complete case-control sets from the selected maternity units; a further 74 sets were obtained from the Cardiff births survey. The analyses in tables 1-4 were based on these case-control sets.

Table 1 Odds ratios for childhood cancer after vitamin $\mathrm{K}$ prophylaxis for all hospitals with selective policies

\begin{tabular}{|c|c|c|c|c|c|}
\hline \multirow{2}{*}{$\begin{array}{l}\text { Diagnostic group and } \\
\text { factor analysed }\end{array}$} & \multirow[b]{2}{*}{ Odds ratio $(95 \% \mathrm{CI})$} & \multirow[b]{2}{*}{$P$ value } & \multirow{2}{*}{$\begin{array}{c}\begin{array}{c}\text { No of } \\
\text { discordant } \\
\text { sets }\end{array} \\
\end{array}$} & \multicolumn{2}{|c|}{$\begin{array}{c}\text { Vitamin } \mathrm{K} \text { effect allowing for } \\
\text { other factors }\end{array}$} \\
\hline & & & & Odds ratio & $P$ value \\
\hline \multicolumn{6}{|l|}{ All cancers } \\
\hline Intramuscular vitamin $\mathrm{K}$ & 1.44 (1.00 to 2.08$)$ & 0.05 & 120 & & \\
\hline Birth weight & $0.62(0.29$ to 1.33$)$ & 0.21 & 30 & 1.56 & 0.02 \\
\hline Special care baby unit & 0.95 (0.55 to 1.64$)$ & 0.85 & 52 & 1.57 & 0.03 \\
\hline Delivery & 1.58 (1.10 to 2.28$)$ & 0.01 & 122 & 1.07 & 0.82 \\
\hline Gestation & $0.51(0.25$ to 1.04$)$ & 0.06 & 35 & 1.55 & 0.02 \\
\hline
\end{tabular}

\section{All leukaemias}

\begin{tabular}{|c|c|c|c|c|c|}
\hline Intramuscular vitamin $\mathrm{K}$ & 1.53 (0.82 to 2.85$)$ & 0.17 & 42 & & \\
\hline Birth weight & $1.00(0.31$ to 3.20$)$ & 1.00 & 12 & 1.61 & 0.15 \\
\hline Special care baby unit & 1.23 (0.54 to 2.81$)$ & 0.62 & 23 & 1.59 & 0.20 \\
\hline Delivery & 2.62 (1.31 to 5.24$)$ & 0.005 & 38 & 0.71 & 0.45 \\
\hline Gestation & $0.68(0.24$ to 1.87$)$ & 0.45 & 16 & 1.60 & 0.14 \\
\hline \multicolumn{6}{|l|}{ Non-leukaemia cancers } \\
\hline Intramuscular vitamin $\mathrm{K}$ & $1.39(0.88$ to 2.20$)$ & 0.15 & 78 & & \\
\hline Birth weight & $0.44(0.16$ to 1.24$)$ & 0.10 & 18 & 1.51 & 0.08 \\
\hline Special care baby unit & 0.77 (0.37 to 1.62$)$ & 0.49 & 29 & 1.54 & 0.08 \\
\hline Delivery & $1.27(0.82$ to 1.97$)$ & 0.28 & 84 & 1.39 & 0.35 \\
\hline Gestation & $0.39(0.14$ to 1.09$)$ & 0.06 & 19 & 1.53 & 0.07 \\
\hline \multicolumn{6}{|c|}{ Acute lymphoblastic leukaemia } \\
\hline Intramuscular vitamin $\mathrm{K}$ & 1.73 (0.89 to 3.34$)$ & 0.10 & 38 & & \\
\hline Birth weight & $1.00(0.31$ to 3.20$)$ & 1.00 & 12 & 1.86 & 0.08 \\
\hline Special care baby unit & 1.48 (0.62 to 3.52$)$ & 0.38 & 21 & 1.69 & 0.16 \\
\hline Delivery & 3.19 (1.47 to 6.92$)$ & 0.002 & 33 & 0.80 & 0.64 \\
\hline Gestation & $0.86(0.30$ to 2.51$)$ & 0.79 & 14 & 1.76 & 0.09 \\
\hline \multicolumn{6}{|c|}{ Acute lymphoblastic leukaemia ages 1-5 years } \\
\hline Intramuscular vitamin $\mathrm{K}$ & $1.03(0.48$ to 2.20$)$ & 0.95 & 27 & & \\
\hline Birth weight & $0.59(0.15$ to 2.33$)$ & 0.44 & 10 & 1.14 & 0.75 \\
\hline Special care baby unit & $1.22(0.47$ to 3.18$)$ & 0.68 & 17 & 0.91 & 0.84 \\
\hline Delivery & $1.90(0.82$ to 4.41$)$ & 0.13 & 24 & 0.56 & 0.26 \\
\hline Gestation & $0.86(0.30$ to 2.51$)$ & 0.79 & 14 & 1.04 & 0.92 \\
\hline
\end{tabular}


Table 2 Odds ratios for childhood cancer after vitamin $\mathrm{K}$ prophylaxis for "selected maternity units" (see text) with selective policies

\begin{tabular}{|c|c|c|c|c|c|}
\hline \multirow{2}{*}{$\begin{array}{l}\text { Diagnostic group and } \\
\text { factor analysed }\end{array}$} & \multirow[b]{2}{*}{ Odds ratio $(95 \% \mathrm{CI})$} & \multirow[b]{2}{*}{$P$ value } & \multirow{2}{*}{$\begin{array}{l}\text { No of } \\
\text { discordant } \\
\text { sets }\end{array}$} & \multicolumn{2}{|c|}{$\begin{array}{l}\text { Vitamin K effect allowing } \\
\text { for other factors }\end{array}$} \\
\hline & & & & Odds ratio & $P$ value \\
\hline \multicolumn{6}{|l|}{ All cancers } \\
\hline Intramuscular vitamin $\mathrm{K}$ & $1.19(0.77$ to 1.86$)$ & 0.43 & 79 & & \\
\hline Birth weight & $0.58(0.23$ to 1.47$)$ & 0.25 & 19 & 1.30 & 0.26 \\
\hline Special care baby unit & $0.91(0.51$ to 1.65$)$ & 0.76 & 44 & 1.30 & 0.30 \\
\hline Delivery & 1.30 (0.83 to 2.05$)$ & 0.25 & 76 & 0.98 & 0.95 \\
\hline Gestation & $0.42(0.18$ to 0.96$)$ & 0.03 & 27 & 1.32 & 0.24 \\
\hline \multicolumn{6}{|l|}{ All leukaemias } \\
\hline Intramuscular vitamin $\mathrm{K}$ & $1.50(0.73$ to 3.10$)$ & 0.27 & 30 & & \\
\hline Birth weight & $1.00(0.20$ to 4.92$)$ & 1.00 & 6 & 1.60 & 0.24 \\
\hline Special care baby unit & $1.38(0.56$ to 3.40$)$ & 0.49 & 19 & 1.48 & 0.39 \\
\hline Delivery & $2.13(0.92$ to 4.92$)$ & 0.07 & 25 & 0.89 & 0.83 \\
\hline Gestation & $0.63(0.21$ to 1.90$)$ & 0.40 & 13 & 1.64 & 0.19 \\
\hline \multicolumn{6}{|l|}{ Non-leukaemia cancers } \\
\hline Intramuscular vitamin K & $1.04(0.60$ to 1.82$)$ & 0.89 & 49 & & \\
\hline Birth weight & $0.44(0.14$ to 1.42$)$ & 0.16 & 13 & 1.13 & 0.67 \\
\hline Special care baby unit & 0.67 (0.30 to 1.48$)$ & 0.32 & 25 & 1.19 & 0.58 \\
\hline Delivery & $1.04(0.60$ to 1.80$)$ & 0.89 & 51 & 1.03 & 0.95 \\
\hline Gestation & 0.27 (0.08 to 0.98$)$ & 0.03 & 14 & 1.15 & 0.63 \\
\hline \multicolumn{6}{|c|}{ Acute lymphoblastic leukaemia } \\
\hline Intramuscular vitamin $\mathrm{K}$ & 1.55 (0.73 to 3.28$)$ & 0.26 & 28 & & \\
\hline Birth weight & $1.00(0.20$ to 4.92$)$ & 1.00 & 6 & 1.67 & 0.22 \\
\hline Special care baby unit & $1.57(0.61$ to 4.03$)$ & 0.34 & 18 & 1.40 & 0.47 \\
\hline Delivery & $2.14(0.87$ to 5.26$)$ & 0.08 & 22 & 0.98 & 0.96 \\
\hline Gestation & $0.83(0.26$ to 2.72$)$ & 0.76 & 11 & 1.60 & 0.23 \\
\hline \multicolumn{6}{|c|}{ Acute lymphoblastic leukaemia ages 1-5 years } \\
\hline Intramuscular vitamin $\mathrm{K}$ & $1.10(0.47$ to 2.58$)$ & 0.83 & 21 & & \\
\hline Birth weight & $0.67(0.11$ to 3.95$)$ & 0.65 & 5 & 1.23 & 0.67 \\
\hline Special care baby unit & $1.14(0.42$ to 3.14$)$ & 0.80 & 15 & 1.04 & 0.94 \\
\hline Delivery & 1.29 (0.48 to 3.44$)$ & 0.62 & 16 & 0.92 & 0.89 \\
\hline Gestation & 0.83 (0.26 to 2.72) & 0.76 & 11 & 1.13 & 0.78 \\
\hline
\end{tabular}

Odds ratios (95\% confidence intervals) for intramuscular vitamin $\mathrm{K}$ and other perinatal factors in relation to the occurrence of childhood cancer are shown in table 1 for all cases born in hospitals or periods with a selective vitamin K policy. Results from the selected maternity units and from the Cardiff births survey are given separately in tables 2 and 3 . Table 4 shows the odds ratios for factors other than vitamin $\mathrm{K}$ in the hospitals where there was a non-selective vitamin K policy. Odds ratios were calculated for all childhood cancers taken together and for various subgroups. In particular we analysed results for acute lymphoblastic leukaemia at ages 1-5 years, in response to the suggestion (Parker et al in this issue ${ }^{12}$ ) that the postulated carcinogenic risk of vitamin $\mathrm{K}$ is concentrated in this group.

For intramuscular vitamin $\mathrm{K}$ the odds ratio for all cancers for the combined group was 1.44 and was of borderline significance $(\mathrm{P}=0.05)$; for leukaemia it was $1.53(\mathrm{P}=0.17)$; and for cases of acute lymphoblastic leukaemia diagnosed at ages $1-5$ years it was 1.03 (see table 1). The largest odds ratio was $2.43(\mathrm{P}=0.03)$ and was for cancers other than leukaemia in the Cardiff births survey. The corresponding odds ratio for the other hospitals was 1.04. None of the findings in selected maternity units was significant; there is little consistency between these results and those from the Cardiff births survey.

In both groups there was a raised risk of leukaemia associated with abnormal delivery. Estimates of the effect of vitamin $\mathrm{K}$ after we allowed for the effects of this and other possible confounding factors are shown in the last two columns of tables 1-3. Whenever there was a significant vitamin $K$ effect it became non-significant when the effect of type of delivery was taken into account. The estimated vitamin $\mathrm{K}$ effect for cancers other than leukaemia in the Cardiff births survey did, however, increase when we allowed for the effect of delivery. Some of the vitamin $\mathrm{K}$ odds ratios became greater or more significant when we allowed for birth weight, admission to special care baby units, or short gestation.

\section{Data quality and verification}

The characteristics of the controls were examined to ensure that no bias had occurred because more effort would be spent looking for notes for cases than for controls. There were no differences in type of delivery, birth weight, admission to special care baby units, or gestation between controls selected as a result of the first and second attempts in the procedure described above.

Another potential source of error is the incorrect abstraction of medical records. To estimate the proportion of babies for whom the vitamin $\mathrm{K}$ information had been incorrectly abstracted we re-examined 148 records. Intramuscular vitamin $\mathrm{K}$ was recorded as having been given in four cases and two controls when it had not been noted previously, but in each case it complied with the current stated hospital policy. There were two discrepancies in birth weight and no discrepancies in information about admission to special care baby units or type of delivery or gestation calculated by using the expected date of delivery.

\section{Discussion}

Although we have found some positive results, these were not consistent for the different parts of the study, and the results of the analyses of vitamin $\mathrm{K}$ with allowance for other variables are difficult to interpret; the most obvious explanation for some of the findings is that they are attributable to the small numbers of cases in certain categories and the nature of the statistical models.

If the association between intramuscular vitamin $\mathrm{K}$ and childhood cancer is not causal we need to consider other possible explanations of the findings. Obviously the results could be due to chance. There could be some systematic bias in the study design, though the study methods have been reviewed and no such bias has been established. The finding may be explained by association between vitamin $\mathrm{K}$ and other factors, particularly abnormal delivery, though there was no significant effect of delivery in the non-selective group of hospitals (see table 4) or in general in other studies not cited here. For hospitals that use a selective policy there is a close relation between abnormal delivery and the use of vitamin $\mathrm{K}$. This makes it difficult to determine which, if either, of these is causally related to the subsequent development of cancer. If the association with abnormal delivery is real it is unlikely that the type of delivery itself causes the effect. This raises the question of whether fetal abnormalities or drugs associated with the abnormal deliveries could explain the effect. Other possible explanations would apply generally to case-control studies of this 
problem-for instance, children who develop leukaemia may be more likely to experience ill health early in life and to be given intramuscular vitamin $\mathrm{K}$.

\section{Summary of all studies}

The finding in two studies by Golding et $\mathrm{al}^{12}$ of an association between childhood cancer and the use of intramuscular vitamin K (usually Konakion) to prevent vitamin $\mathrm{K}$ deficiency bleeding among newborns has never been satisfactorily explained. There is debate about whether the association is biologically plausible, and it has not been confirmed by subsequent studies. The findings from these two studies, from the other five that have been published previously, and from this and the accompanying three papers in this issue are summarised in table $5 .{ }^{12-14}$

Klebanoff et al carried out a small case-control study in children aged 0-7 years and reported relative risks less than unity (but with wide confidence intervals) both for leukaemias and for all cancers together. ${ }^{7}$ Ekelund et al compared cumulative incidence rates for children born after non-instrumental deliveries in Swedish maternity units that gave either intramuscular or oral vitamin $\mathrm{K}$ during the period 1973-89. For the whole period, and including cases diagnosed up to age 18 , the relative risk associated with intramuscular vitamin $\mathrm{K}$ for all cancers was 1.01 , that for leukaemia being 0.90 . For ages $0-9$, only the results for 1982-9 are reported. These give point estimates of 1.11 and 1.20, respectively, though with confidence limits including unity. ${ }^{4}$ Olsen et al compared cumulative rates among Danish children born during years when vitamin $\mathrm{K}$ was not used with those born in years when intramuscular doses were given to all newborns. The relative risks, defined as the ratio of the cumulative risks for these two groups at age 13 (described in the paper as ages 1-13 and here as 0-12) are given in table 5 . That for leukaemia is unity. The significantly raised relative risk for all cancers is explained by the authors as being due to previously reported continuous increases in the rates for lymphomas and neuroblastomas. ${ }^{5}$ Von Kries et al carried out a case-control study in Germany of 272 children with leukaemia, nephroblastoma, neuroblastoma, rhabdomyoblastoma, and tumours of the central nervous system who were aged 30 days to 15 years at diagnosis. They failed to find a significant association with intramuscular vitamin $\mathrm{K}$ for any diagnosis, except possibly acute lymphoblastic leukaemia, for which they quote odds ratios greater than 2 with significant $P$ values but with confidence intervals that include unity. ${ }^{6}$ (The explanation for this apparent anomaly is that they used one sided significance tests, and the results would not be significant with a two sided $5 \%$ significance level.) Ansell et al, in a case-control study of childhood leukaemia in three large hospitals in England, found no significant association with intramuscular vitamin $\mathrm{K}$ for acute lymphoblastic leukaemia or for all leukaemias. $^{3}$

The other papers in this issue show largely negative results. Parker et al ( $p$ 189), however, found an increased risk of acute lymphoblastic leukaemia in an analysis of the age group 1-5 years (which was performed to include the childhood peak of acute lymphoblastic leukaemia). ${ }^{12}$ Their odds ratio for other cancers is less than 1 . The paper by McKinney et al is different from most of the others in that the case defi-
Table 3 Odds ratios for childhood cancer after vitamin $\mathrm{K}$ prophylaxis for Cardiff births survey (all had selective policy)

\begin{tabular}{|c|c|c|c|c|c|}
\hline \multirow{2}{*}{$\begin{array}{l}\text { Diagnostic group and } \\
\text { factor analysed }\end{array}$} & \multirow[b]{2}{*}{ Odds ratio $(95 \% \mathrm{Cl})$} & \multirow[b]{2}{*}{$P$ value } & \multirow{2}{*}{$\begin{array}{l}\text { No of } \\
\text { discordant } \\
\text { sets }\end{array}$} & \multicolumn{2}{|c|}{$\begin{array}{l}\text { Vitamin } K \text { effect allowing for } \\
\text { other factors }\end{array}$} \\
\hline & & & & odds ratio & $P$ value \\
\hline \multicolumn{6}{|l|}{ All cancers } \\
\hline Intramuscular vitamin $\mathrm{K}$ & $2.14(1.11$ to 4.11$)$ & 0.02 & 41 & & \\
\hline Birth weight & 0.70 (0.18 to 2.65$)$ & 0.59 & 11 & 2.26 & 0.02 \\
\hline Special care baby unit & $1.20(0.29$ to 5.02$)$ & 0.80 & 8 & 2.17 & 0.02 \\
\hline Delivery & $2.23(1.21$ to 4.11$)$ & 0.01 & 46 & 1.33 & 0.56 \\
\hline Gestation & $1.00(0.23$ to 4.35$)$ & 1.00 & 8 & 2.16 & 0.02 \\
\hline \multicolumn{6}{|l|}{ All leukaemias } \\
\hline Intramuscular vitamin $\mathrm{K}$ & $1.62(0.51$ to 5.18$)$ & 0.42 & 12 & & \\
\hline Birth weight & $1.00(0.18$ to 5.46$)$ & 1.00 & 6 & 1.67 & 0.41 \\
\hline Special care baby unit & $0.67(0.07$ to 6.40$)$ & 0.72 & 4 & 1.73 & 0.38 \\
\hline Delivery & 3.84 (1.16 to 12.65$)$ & 0.02 & 13 & 0.34 & 0.29 \\
\hline Gestation & 1.00 (0.09 to 11.02$)$ & 1.00 & 3 & 1.62 & 0.42 \\
\hline \multicolumn{6}{|l|}{ Non-leukaemia cancers } \\
\hline Intramuscular vitamin $\mathrm{K}$ & 2.43 (1.09 to 5.40$)$ & 0.03 & 29 & & \\
\hline Birth weight & $0.43(0.05$ to 3.86$)$ & 0.41 & 5 & 2.64 & 0.02 \\
\hline Special care baby unit & 2.00 (0.28 to 14.19$)$ & 0.49 & 4 & 2.39 & 0.03 \\
\hline Delivery & 1.79 (0.87 to 3.69$)$ & 0.11 & 33 & 2.79 & 0.11 \\
\hline Gestation & $1.00(0.16$ to 6.42$)$ & 1.00 & 5 & 2.57 & 0.02 \\
\hline \multicolumn{6}{|c|}{ Acute Iymphoblastic leukaemia } \\
\hline Intramuscular vitamin $\mathrm{K}$ & 2.38 (0.65 to 8.73$)$ & 0.19 & 10 & & \\
\hline Birth weight & $1.00(0.18$ to 5.46$)$ & 1.00 & 6 & 2.57 & 0.17 \\
\hline Special care baby unit & $1.00(0.09$ to 11.02$)$ & 1.00 & 3 & 2.39 & 0.19 \\
\hline Delivery & 7.59 (1.61 to 35.71$)$ & 0.003 & 11 & 0.53 & 0.56 \\
\hline Gestation & 1.00 (0.09 to 11.02$)$ & 1.00 & 3 & 2.40 & 0.18 \\
\hline \multicolumn{6}{|c|}{ Acute lymphoblastic leukaemia ages 1-5 years } \\
\hline Intramuscular vitamin $\mathrm{K}$ & $0.77(0.13$ to 4.48$)$ & 0.77 & 6 & & \\
\hline Birth weight & $0.50(0.06$ to 4.46$)$ & 0.51 & 5 & 0.85 & 0.86 \\
\hline Special care baby unit & $2.00(0.13$ to 31.93$)$ & 0.63 & 2 & 0.65 & 0.65 \\
\hline Delivery & 4.65 (0.91 to 23.59$)$ & 0.05 & 8 & Calculation failed & \\
\hline Gestation & 1.00 (0.09 to 11.02$)$ & 1.00 & 3 & 0.77 & 0.77 \\
\hline
\end{tabular}

Table 4 Odds ratios for childhood cancer after vitamin $\mathrm{K}$ prophylaxis for hospitals with non-selective policies

\begin{tabular}{|c|c|c|c|}
\hline $\begin{array}{l}\text { Diagnostic group and factor } \\
\text { analysed }\end{array}$ & Adjusted odds ratio ( $95 \% \mathrm{Cl}$ ) & $P$ value & $\begin{array}{c}\text { No of discordant } \\
\text { sets }\end{array}$ \\
\hline \multicolumn{4}{|l|}{ All cancers } \\
\hline Birth weight & $0.57(0.24$ to 1.35$)$ & 0.20 & 22 \\
\hline Special care baby unit & $0.94(0.57$ to 1.54$)$ & 0.80 & 62 \\
\hline Delivery & $0.84(0.59$ to 1.21$)$ & 0.36 & 118 \\
\hline Gestation & 0.83 (0.36 to 1.92) & 0.67 & 22 \\
\hline \multicolumn{4}{|l|}{ All leukaemias } \\
\hline Birth weight & $0.67(0.24$ to 1.86$)$ & 0.44 & 15 \\
\hline Special care baby unit & 0.69 (0.32 to 1.48$)$ & 0.33 & 27 \\
\hline Delivery & 1.03 (0.63 to 1.69$)$ & 0.90 & 63 \\
\hline Gestation & $1.00(0.29$ to 3.44$)$ & 1.00 & 10 \\
\hline \multicolumn{4}{|l|}{ Non-leukaemia cancers } \\
\hline Birth weight & $0.40(0.08$ to 2.01$)$ & 0.25 & 7 \\
\hline Special care baby unit & 1.19 (0.61 to 2.30$)$ & 0.61 & 35 \\
\hline Delivery & $0.67(0.39$ to 1.14$)$ & 0.14 & 55 \\
\hline Gestation & 0.71 (0.23 to 2.24$)$ & 0.56 & 12 \\
\hline \multicolumn{4}{|l|}{ Acute Iymphoblastic leukaemia } \\
\hline Birth weight & 0.29 (0.06 to 1.37$)$ & 0.09 & 9 \\
\hline Special care baby unit & $0.43(0.16$ to 1.12$)$ & 0.07 & 20 \\
\hline Delivery & 0.96 (0.55 to 1.68$)$ & 0.89 & 49 \\
\hline Gestation & 0.50 (0.09 to 2.69$)$ & 0.41 & 6 \\
\hline \multicolumn{4}{|c|}{ Acute lymphoblastic leukaemia ages 1-5 years } \\
\hline Birth weight & $0.33(0.07$ to 1.65$)$ & 0.15 & 8 \\
\hline Special care baby unit & 0.40 (0.13 to 1.28$)$ & 0.10 & 14 \\
\hline Delivery & 1.25 (0.65 to 2.41$)$ & 0.50 & 36 \\
\hline Gestation & $0.50(0.09$ to 2.69$)$ & 0.41 & 6 \\
\hline
\end{tabular}

nition was based on year of diagnosis rather than year of birth, and they studied a more recently diagnosed 
Table 5 Summary of estimated relative risks from 12 studies. Figures are unadjusted odds ratios (with or without $95 \%$ confidence intervals) unless stated otherwise

\begin{tabular}{|c|c|c|c|c|c|c|c|c|c|}
\hline Study & $\begin{array}{l}\text { Type of } \\
\text { study* }^{*}\end{array}$ & $\begin{array}{l}\text { Intramuscular } \\
\text { vitamin K } \\
\text { versus: }\end{array}$ & $\begin{array}{c}\text { Age } \\
\text { groupt }\end{array}$ & All cancers & Leukaemia & ALL 1-5 years† & Non-leukaemia & $\begin{array}{l}\% \text { Recording } \\
\text { of vitamin K }\end{array}$ & $\begin{array}{l}\text { No of } \\
\text { cases }\end{array}$ \\
\hline Golding, $1990^{1}$ & Cohort & & $0-10$ years & $\begin{array}{c}2.62 \\
(1.31 \text { to } 5.21)\end{array}$ & - & - & - & & 33 \\
\hline Golding, $1992^{2}$ & Case-control & Oral or none & $0-14$ years & $\begin{array}{c}2.16 \\
(1.27 \text { to } 3.67) \\
\end{array}$ & $\begin{array}{c}2.65 \\
\text { (1.34 to } 5.24)\end{array}$ & - & $\begin{array}{c}1.72 \\
(1.04 \text { to } 2.84)\end{array}$ & & 195 \\
\hline $\begin{array}{c}\text { Klebanoff, } \\
1993^{7} \\
\end{array}$ & Case-control & $\begin{array}{l}\text { None/oral or } \\
\text { no record }\end{array}$ & $0-7$ years & $\begin{array}{c}0.84 \\
(0.41 \text { to } 1.71) \\
\end{array}$ & $\begin{array}{c}0.47 \\
(0.14 \text { to } 1.55) \\
\end{array}$ & - & $\begin{array}{c}1.08 \\
(0.45 \text { to } 2.61)\end{array}$ & & 44 \\
\hline Ekelund, $1993^{4}$ & Ecologicalł & Oral & $0-9$ years & $\begin{array}{c}1.11 \\
(0.88 \text { to } 1.40)\end{array}$ & $\begin{array}{c}1.20 \\
(0.69 \text { to } 2.08)\end{array}$ & - & - & $50 \%$ & NA \\
\hline Olsen, $1994^{5}$ & Ecological $\ddagger$ & $\begin{array}{l}\text { None/oral or } \\
\text { no record }\end{array}$ & $0-12$ years & $\begin{array}{c}1.29 \\
(1.23 \text { to } 1.35) \\
\end{array}$ & $\begin{array}{c}1.00 \\
\text { (0.93 to } 1.09)\end{array}$ & - & - & & NA \\
\hline $\begin{array}{c}\text { Von Kries, } \\
1996^{6}\end{array}$ & Case-control & Oral or none & $0-14$ years & - & $\begin{array}{c}1.24 \\
(0.68 \text { to } 2.25)\end{array}$ & $\begin{array}{c}2.28 \\
(0.94 \text { to } 5.54)\end{array}$ & $\begin{array}{c}1.19 \\
(0.77 \text { to } 1.83)\end{array}$ & $70 \%$ & 272 \\
\hline Ansell, $1996^{3}$ & Case-control & Oral or none & $0-14$ years & - & $\begin{array}{c}1.3 \\
(0.7 \text { to } 2.3) \\
(0 \mathrm{R}=1.2 \S)\end{array}$ & - & - & $70 \%$ & 132 \\
\hline Parker, $1998^{12}$ & Case-control & $\begin{array}{l}\text { None/oral or } \\
\text { no record }\end{array}$ & $0-14$ years & $\begin{array}{c}0.89 \\
(0.69 \text { to } 1.15)\end{array}$ & $\begin{array}{c}1.2 \\
(0.75 \text { to } 1.92) \\
(A L L)\end{array}$ & $\begin{array}{c}1.79 \\
(1.02 \text { to } 3.15) \\
(0 R=2.57 \S)\end{array}$ & $<1$ & & 685 \\
\hline Parker, $1998^{12}$ & Ecologicalf & & $1-5$ years & - & - & $1.05,0.94 \rrbracket$ & - & & $250,64 \pi$ \\
\hline $\begin{array}{l}\text { Passmore, } 1998 \\
\text { (this paper) }\end{array}$ & Case-control & Oral or none & $1-14$ years & $\begin{array}{c}1.44 \\
(1.00 \text { to } 2.08) \\
(0 R=1.07 \S)\end{array}$ & $\begin{array}{c}1.53 \\
(0.82 \text { to } 2.85) \\
(0 \mathrm{R}=0.71 \S)\end{array}$ & $\begin{array}{c}1.03 \\
(0.48 \text { to } 2.20) \\
(0 R=0.56 \S)\end{array}$ & $\begin{array}{c}1.39 \\
(0.88 \text { to } 2.20) \\
(0 R=1.39 \S)\end{array}$ & $50 \%$ & 597 \\
\hline $\begin{array}{c}\text { Passmore, } \\
1998^{14}\end{array}$ & Ecologicalł & & $1-14$ years & $1.03,1.06^{* *}$ & $1.13,1.14^{\star \star}$ & $1.14,1.07^{\star \star}$ & $0.97,1.01^{* *}$ & & $\begin{array}{l}2300 \\
966^{\star \star}\end{array}$ \\
\hline $\begin{array}{c}\text { McKinney, } \\
1998^{13}\end{array}$ & Case-control & & $0-14$ years & - & $\begin{array}{c}1.30 \\
(0.83 \text { to } 2.03) \\
(0 R=1.23 \S)\end{array}$ & $\begin{array}{c}1.08 \\
(0.60 \text { to } 1.94) \\
(0 R=1.16 \S)\end{array}$ & - & & 82 \\
\hline
\end{tabular}

$\mathrm{ALL}=$ Acute lymphoblastic leukaemia.

${ }^{*}$ Cohort study includes only one study (Golding et al, 1990) in which exposure and follow up information was available for individual children; when information on vitamin $\mathrm{K}$ exposure was available only for groups of births, term ecological study used; not all authors make this distinction.

†Age 0-9 means from birth to 10th birthday; age 1-14 means from 1st to 15th birthday. Similarly for other ranges; not all authors adhere to this convention. In category ALL 1-5 years all except for McKinney are risks for children diagnosed from 12-71 months, inclusive; McKinney risk is for 12-83 months. If more than one age range is quoted, we have chosen that which is as close as possible to 1-14 and does not go beyond this age range.

fOdds ratios for ecological studies (based on comparisons between groups whose average exposure is known) will tend to underestimate any true effect (see accompanying paper by Passmore et al, $p$ 184).

$\S 0 d d s$ ratio adjusted for delivery (and also, in paper by Ansell et al, for admission to special care baby units; for McKinney adjusted for delivery plus social deprivation).

१First figure refers to comparisons between hospitals/periods with non-selective and selective policies; second figure gives result for same comparison with results only from hospitals where both policies had been used.

${ }^{\star *}$ First figure is comparison between hospitals with non-selective and those with selective policies; second figure is comparison between policies for hospitals where policies changed.

group of children. None of the odds ratios was significant, and the odds ratio for acute lymphoblastic leukaemia at ages 1-6 (they analysed this age group rather than 1-5) was 1.08 (0.6 to 1.94) for recorded and 1.24 (0.68 to 2.28 ) for imputed data. ${ }^{13} 14$

Our accompanying paper ( $\mathrm{p} 184$ ) gives the results of an ecological study. Such studies are less sensitive to the effects of misclassification of vitamin $\mathrm{K}$ status. Though generally negative, the results are consistent with there being an effect of vitamin $\mathrm{K}$ on incidence of leukaemia, though again much smaller than that suggested by Golding and with no indication of an effect on other cancers.

In view of the inconsistency of the results between the various studies it seems unlikely that there is a risk for intramuscular vitamin $\mathrm{K}$ of the magnitude suggested by Golding et al; but we cannot exclude the possibility of a small risk. The association found here between abnormal delivery and childhood leukaemia may explain some of the previously reported effects of vitamin $\mathrm{K}$ as most hospitals have a policy of giving intramuscular vitamin $\mathrm{K}$ in such cases.

\section{Policy implications}

In their second paper Golding et al considered the question of whether the benefits of prophylactic vitamin $\mathrm{K}$ in preventing vitamin $\mathrm{K}$ deficiency bleeding outweigh the possible costs in terms of resulting cancers. ${ }^{2}$ They concluded that if there was a doubling of the risk "the prophylactic benefits against haemorrhagic disease are unlikely to exceed the potential adverse effects from intramuscular vitamin K."

It now seems likely that the risk, if any, is lower, but epidemiological studies may be unable to exclude it entirely. It is important therefore to consider, for possible policies of vitamin $\mathrm{K}$ prophylaxis, both the benefits in terms of prevention of vitamin $\mathrm{K}$ deficiency bleeding and the costs if we assume that there is an increased probability of childhood cancer. The possible consequences of various alternative policies are set out below and in table 6 .

Little information is available about the effectiveness of the different forms of prophylaxis for vitamin $\mathrm{K}$ deficiency bleeding. The assumptions given here are based on discussions with Andrew McNinch and the paper by Cornellisen et al. ${ }^{15}$ For babies not recognised clinically as being at risk and having no prophylaxis the incidence of such bleeding is estimated as 100 per million; for those given intramuscular vitamin $\mathrm{K}$ it is estimated to be about 1 per million. Several different regimens for oral prophylaxis are in use, varying in details such as the vitamin $\mathrm{K}$ preparation used, the dose, and the frequency of administration; for normal 
babies the quoted incidence of failures of prophylaxis after such regimens varies from 2 to 36 per million.

Good information is available about the incidence of childhood cancer, though if some cases are caused by vitamin $\mathrm{K}$ we cannot say what the current incidence would be in the absence of vitamin K. But for the illustrations given here the precise rates are not important; we assume that the risk by the age of 15 years is about 1 in 600 (167 per 100000$)$ in a population with no vitamin $\mathrm{K}$ prophylaxis. On the basis of the existing studies we cannot exclude the possibility that the risk of childhood cancer after intramuscular vitamin $\mathrm{K}$ prophylaxis is increased by $5 \%$ or even $10 \%$-that is, to a rate of 175 or 183 per 100000 . (The risk of cancer, if any, is assumed to be the same for all forms of intramuscular vitamin $\mathrm{K}$, though most of the studies have concerned Konakion; it is also assumed that there is no risk from oral preparations). Using the assumptions of a $5 \%$ or $10 \%$ increase in risk we consider the effects on cancer and vitamin $\mathrm{K}$ deficiency bleeding in 800000 births (over the past decade the annual number of births in the United Kingdom has varied from about 730000 to about 790 000) for four possible prophylaxis policies: firstly, no routine prophylaxis-only those (assumed to be about $10 \%$ ) clinically recognised as highest risk babies are treated with intramuscular vitamin $\mathrm{K}$; secondly, all newborns are given $1 \mathrm{mg}$ intramuscular vitamin K (standard prophylaxis); thirdly, about 30\% "high risk" babies, as defined in the introduction, are given standard prophylaxis; the rest are given oral prophylaxis; finally, only the $10 \%$ at highest risk are given standard prophylaxis, the rest being given oral.

The predicted additional numbers of cases of childhood cancer (that is, as compared with what would occur if there was no carcinogenic risk from vitamin K) and of cases of vitamin K deficiency bleeding prevented after these policies are given in table 6 . We assume that among those suffering vitamin $\mathrm{K}$ deficiency bleeding about one third would suffer serious harm-that is, brain damage or death. The numbers of additional cancers should therefore be compared with one third of the numbers of cases of vitamin $\mathrm{K}$ deficiency bleeding that are prevented. On the assumption of a $5 \%$ or $10 \%$ increase in risk of cancer with a dose of $1 \mathrm{mg}$ intramuscular vitamin $\mathrm{K}$, there is no net benefit in extending such prophylaxis beyond the highest risk group containing around $10 \%$ or fewer babies (for whom oral prophylaxis may be inadequate). On the basis of these calculations oral prophylaxis should be used for the remainder. If it could be shown that a smaller intramuscular dose is effective prophylaxis, and if we assume any risk of cancer then decreases, there could be a net benefit from treating a greater proportion with the intramuscular form.

Finally, it should be remembered that bleeding from the nose, umbilical stump, or gastrointestinal tract is not normal in babies and should be investigated urgently and also that vitamin $\mathrm{K}$ deficiency bleeding should be considered as a possible complication of prolonged neonatal jaundice.

\section{Conclusions}

In this study we have found an association between vitamin $\mathrm{K}$ and childhood cancer, but the association with abnormal deliveries might explain this. The inconsistencies in the results from the studies summa-
Table 6 Estimated effects of various prophylaxis policies on numbers of cases of vitamin $\mathrm{K}$ deficiency bleeding and childhood cancer occurring among 800000 children if risk of childhood cancer is increased by use of intramuscular vitamin $\mathrm{K}$ (see text for details of assumptions)

\begin{tabular}{|c|c|c|c|c|}
\hline \multirow[b]{2}{*}{ Prophylaxis policy } & \multicolumn{2}{|c|}{ Vitamin $\mathrm{K}$ deficiency bleeding } & \multicolumn{2}{|c|}{$\begin{array}{l}\text { Additional childhood cancers if } \\
\text { risk is increased by: }\end{array}$} \\
\hline & $\begin{array}{c}\text { Cases } \\
\text { occurring* }\end{array}$ & $\begin{array}{l}\text { Cases prevented in } \\
\text { addition to the } 10 \% \\
\text { at "highest risk"* }\end{array}$ & $5 \%$ & $10 \%$ \\
\hline $\begin{array}{l}\text { No routine prophylaxis; only } \\
\text { those recognised clinically to } \\
\text { be at highest risk are treated } \\
\text { (assumed to be } 10 \% \text { ) }\end{array}$ & $72(24)$ & - & 6 & 13 \\
\hline Intramuscular $1 \mathrm{mg}$ to all & $1(0)$ & $71(24)$ & 64 & 128 \\
\hline $\begin{array}{l}\text { Intramuscular } 1 \text { mgt given to } \\
\text { "high risk" babies ( } 30 \% \text { of } \\
\text { total). Oral to remainder }\end{array}$ & $1-20(0-7)$ & $52-71(17-24)$ & 19 & 38 \\
\hline $\begin{array}{l}\text { Intramuscular } 1 \mathrm{mg} \text { given } \\
\text { only to } 10 \% \text { of babies at } \\
\text { highest risk of vitamin } \mathrm{K} \\
\text { deficiency bleeding. Oral to } \\
\text { remainder }\end{array}$ & $2-26(1-9)$ & $46-70(15-23)$ & 6 & 13 \\
\hline
\end{tabular}

${ }^{*}$ Figures in these columns are calculated on the assumption that newborns clinically recognised to be at high risk will all be given intramuscular vitamin $\mathrm{K}$ and that stated prophylaxis policy will be used for remainder. Figures in parentheses are estimates of numbers of babies who would suffer serious harm-that is, die or suffer brain damage.

fln practice some of the babies at high risk would be those of very low birth weight, who would be given doses less than $1 \mathrm{mg}$.

rised here and the relatively low risks found in some of them suggest that there may be no causal association between intramuscular vitamin $\mathrm{K}$ and childhood cancer and that any risk is probably small. In view of the uncertainties surrounding this question, however, it could be considered prudent to determine whether lower doses of intramuscular vitamin $\mathrm{K}$ are effective in preventing vitamin $\mathrm{K}$ deficiency bleeding.

We are grateful to all the many midwives, paediatricians, medical records staff, and others at all the participating hospitals for their help in finding records and specifying the periods during which various prophylaxis policies were in operation; to Dr Andrew McNinch for many helpful discussions on vitamin $\mathrm{K}$

\section{Key messages}

- Intramuscular vitamin $\mathrm{K}$ given to babies is known to be effective in the prevention of vitamin $\mathrm{K}$ deficiency bleeding but it has been suggested that these preparations, or one of their constituents, may increase the risk of childhood cancer

- Most studies have not shown a significant association between childhood cancer and vitamin $\mathrm{K}$ but are unable to exclude the possibility that its use increases the risk of childhood cancer by up to $10 \%$

- Intramuscular vitamin $\mathrm{K}$ has been given to "high risk" babies as part of all the various prophylaxis policies in the United Kingdom; this should continue

- As a small risk cannot at present be excluded it seems prudent to recommend a policy of giving intramuscular vitamin $\mathrm{K}$ only to those babies at particularly high risk and giving it orally to others

- It is essential that a record should be made of whether or not vitamin $\mathrm{K}$ is given and of the preparation, route of administration, and dose 
prophylaxis; to our colleagues Charles Stiller and Tim Vincent for advice and help in using records from the National Registry of Childhood Tumours; and to Dr Joan Andrews of the Welsh Office and Dr Mary Cotter of the Welsh Cancer Registry for inclusion of the Cardiff births survey data. We thank Hilary Bradshaw, Christine Fitz-John, and Jill Van der Veen for collecting data from various locations, including damp and cold basements; Janette Dickson for typing successive drafts; and Martin King for further help with the data. Finally, we thank Dr John Swanson for his help in commenting on this paper and in other ways. This work was undertaken by the Childhood Cancer Research Group.

Contributors: SJP and GD initiated the study and designed the protocol. PB was responsible for setting up and manipulating computer databases. Statistical analyses were carried out by GD and MK. The paper was written jointly by SJP and GD, who are guarantors for the paper.

Funding: This work was funded by the Department of Health; the views expressed in this publication are those of the authors and not necessarily those of the Department of Health.

Conflict of interest: None.

1 Golding J, Paterson M, Kinlen LJ. Factors associated with childhood cancer in a national cohort study. Br J Cancer 1990;62:304-8.

2 Golding J, Greenwood R, Birmingham K, Mott M. Childhood cancer, intramuscular vitamin $\mathrm{K}$, and pethidine given during labour. $B M$ J 1992;305:341-6.

3 Ansell P, Bull D, Roman E. Childhood leukaemia and intramuscular vitamin K: findings from a case-control study. BMJ 1996;313:204-5.
4 Ekelund H, Finnstrom O, Gunnarskog J, Kallen B, Larsson Y Administration of vitamin $\mathrm{K}$ to newborn infants and childhood cancer. BMJ 1993;307:89-91.

5 Olsen JH, Hertz H, Blinkenberg K, Verder H. Vitamin K regimens and incidence of childhood cancer in Denmark. BMJ 1994;308:895-6.

6 Von Kries R, Gobel U, Hachmeister A, Kaletsch U, Michaelis J. Vitamin K and childhood cancer: a population based case-control study in Lower Saxony, Germany. BMJ 1996;313:199-203.

7 Klebanoff MA, Read JS, Mills JL, Shiono PH. The risk of childhood cancer after neonatal exposure to vitamin K. N Engl J Med 1993;329:905-8.

8 Stiller CA, Allen MB, Eatock EM. Childhood cancer in Britain: the National Registry of Childhood Tumours and incidence rates 1978-1987. Eur J Cancer 1995;31A:2028-34.

9 Handel J, Tripp JH. Vitamin K prophylaxis against haemorrhagic disease of the newborn in the United Kingdom. BMJ 1991;303:1109.

10 Breslow NE, Day NE. Statistical methods in cancer research. Vol 1. The analy sis of case-control studies. Lyons: IARC Scientific Publications, 1980. (Publication No 32.)

11 Francis B, Green M, Payne C, eds. The GLIM system: generalized linear interactive modelling. Oxford: Oxford Science Publications, 1993.

12 Parker L, Cole M, Craft AW, Hey E. Neonatal vitamin K administration and childhood cancer in the north of England. BMJ 1998;316:189-93.

13 McKinney PA, Juszczak E, Findlay E, Smith K. Case-control study of childhood leukaemia and cancer in Scotland: findings for neonatal intramuscular vitamin K. BMJ 1998;316:173-7.

14 Passmore J, Draper G, Brownbill P, Kroll M. Ecological studies of relation between hospital policies on neonatal vitamin $\mathrm{K}$ administration and subsequent occurrence of childhood cancer. BMJ 1998;316:184-9.

15 Cornelissen M, von Kries R, Loughnan P, Schubiger G. Prevention of vitamin $\mathrm{K}$ deficiency bleeding: efficacy of different multiple oral dose schedules of vitamin K. Eur J Pediatr 1997;156:126-30.

(Accepted 31 October 1997)
See editorial by

von Kries and

pp 173, 178, 189

230

Childhood Cancer

Research Group,

Oxford, OX2 6HJ

S Jane Passmore,

research officer

Gerald Draper

director

Pat Brownbill,

research programmer

Mary Kroll,

statistician

Correspondence to: Dr Draper gjd@

ccrg.ox.ac.uk

BMJ 1998;316:184-9

\title{
Ecological studies of relation between hospital policies on neonatal vitamin $\mathrm{K}$ administration and subsequent occurrence of childhood cancer
}

\author{
S Jane Passmore, Gerald Draper, Pat Brownbill, Mary Kroll
}

\begin{abstract}
Objective: To investigate the possible link between neonatal administration of intramuscular vitamin $\mathrm{K}$ and childhood cancer.

Design: Ecological studies comparing incidence of cancer in groups of children classified by the vitamin $\mathrm{K}$ policy in operation at their hospital of birth.

Setting: Selected large maternity units in England, Scotland, and Wales.

Subjects: Children born in these units in varying periods between 1966 and 1991.

Main outcome measures: Cancer occurring among these children before age 15 years identified by using the National Registry of Childhood Tumours. Ratios of observed to expected numbers of these conditions calculated for hospitals where the policy was to give all babies intramuscular vitamin $\mathrm{K}$ (non-selective) and where the policy was to use this treatment only for a selected minority of babies at increased risk of vitamin $\mathrm{K}$ deficiency bleeding (selective).

Results: These ratios were calculated for children born in 94 hospitals with varying vitamin K policies. A raised risk was occasionally associated with vitamin $\mathrm{K}$, but the overall results were not significant, and there was no evidence to support the previously suggested doubling of the risk of childhood cancer.
\end{abstract}

Conclusions: On the basis of the results reported here it is unlikely that there is a greatly increased risk of childhood cancer attributable to intramuscular vitamin $\mathrm{K}$ given to newborns, if indeed there is any.

\section{Introduction}

Research carried out after the publication of papers by Golding et al, which reported a possible doubling of risk of childhood cancer after the administration of intramuscular vitamin $\mathrm{K},{ }^{12}$ has suggested that the risk, if any, is not as large as this. In an accompanying paper ( $p$ 178) we describe the background to the present study and our own case-control study. ${ }^{3}$ We also summarise previous studies and give details of policies on the use of vitamin $\mathrm{K}$ in newborns.

In this paper we present the results obtained with an "ecological study." We use this term rather than "cohort study" as only the average level of exposure for each group in the study was (approximately) known. The analysis is based on knowledge of the policies on vitamin $\mathrm{K}$ administration for births in selected hospitals. We do not know for individual births whether the policy was carried out. We assume, however, that it was in most cases; any increase in incidence of cancer for the total group of cases will depend on the carcinogenic risk, if any, of vitamin $\mathrm{K}$ and also on the proportion of babies receiving it. 